\title{
Observations on Aeromonas hydrophila septicaemia in a patient with leukaemia
}

\author{
E. ABRAMS, C. H. ZIERDT, AND J. A. BROWN \\ From the Clinical Pathology Department, Clinical Center, and Laboratory of Chemical Pharmacology, National \\ Cancer Institute, National Institutes of Health, Bethesda, Maryland, USA
}

SYNOPSIS A Gram-negative bacillus isolated from the blood of a leukaemic patient with septicaemia was identified on the basis of common tests as Escherichia coli. However, the organism's antibiogram was atypical of $E$. coli and led to its re-examination and correct identification as Aeromonas hydrophila. A. hydrophila is sensitive to chloramphenicol and tetracycline, characteristics useful in differentiation from $E$. coli. A simple test differentiating this organism from the Enterobacteriaceae is the oxidase test. A. hydrophila is oxidase positive.

This communication records a case of Aeromonascaused septicaemia, successfully treated with drugs after initial difficulty in identifying the organism.

\section{Case Report}

B.W. (NIH 08-02-01), a 14-year-old white boy, was admitted to the Leukaemia Service of the National Cancer Institute with a diagnosis of acute granulocytic leukaemia. Therapy produced a complete remission. Two months later the disease relapsed.

Four weeks before death the patient developed a fever of $40 \cdot 1^{\circ} \mathrm{C}$ associated with nausea, vomiting, abdominal distension, and adynamic ileus. After cultures were obtained antibiotic therapy was empirically begun with intravenous polymyxin B and cephalothin. There was no change in his status. Cultures of the blood were negative. Three and four days later, while still receiving the same antibiotic regimen, further blood cultures were drawn. These grew, in five of six bottles, pure cultures of an organism first thought to be Escherichia coli but later identified as Aeromonas hydrophila. One day later, when the antibiogram of the organism became known, therapy with chloramphenicol sodium succinate $1 \mathrm{~g}$ intravenously every six hours, and kanamycin, $150 \mathrm{mg}$ intravenously every six hours was instituted. These antibiotics were continued for 14 days during which time four blood cultures were negative; the patient became afebrile and the abdominal signs and symptoms resolved. Blood culture two days after cessation of therapy was negative. The neutropenia persisted and he sucReceived for publication 26 November 1970. cumbed to systemic infection with Aspergillus flavus and Candida albicans.

At postmortem examination Aeromonas hydrophila was not isolated.

\section{Discussion}

Strains of Aeromonas hydrophila, a polar flagellated species of the family Pseudomonadaceae, are a diagnostic problem, because of colonial resemblance to Escherichia coli (Enterobacteriaceae). Aeromonas hydrophila often produces reactions similar to those of $E$. coli on the usual differential media. Differentiation between these two species can be made presumptively by the oxidase test, as Aeromonas produces a positive reaction and members of the Enterobacteriaceae a negative reaction.

Antibiotic sensitivity tests were done by a serial dilution micro-technique (MacLowry, Jacqua, and Selapack, 1970a). The resulting antibiogram for two randomly selected Aeromonas isolates from the patient was unlike that seen in about 800 isolates of E. coli previously tested in this laboratory (MacLowry et al, 1970b). The antibiograms are represented in the table. Whereas only 3 and $4 \%$ of $E$. coli were inhibited by $0.8 \mu \mathrm{g} / \mathrm{ml}$ or less of tetracycline and by $3.0 \mu \mathrm{g} / \mathrm{ml}$ or less of chloramphenicol, respectively, the isolates from the patient were inhibited by 0.8 $\mu \mathrm{g} / \mathrm{ml}$ or less of each of these antibiotics. On the other hand, although $98 \%$ of $E$. coli were inhibited by $0.4 \mu \mathrm{g} / \mathrm{ml}$ or less of colistin, the isolates from the patient were not inhibited by $50 \mu \mathrm{g} / \mathrm{ml}$ of colistin.

Antibiograms of seven other previously studied isolates of Aeromonas hydrophila were similar to the 


\begin{tabular}{|c|c|c|c|c|c|c|c|c|}
\hline & \multicolumn{8}{|c|}{ Minimal Inhibitory Concentration $(\mu \mathrm{g} / \mathrm{ml})$} \\
\hline & Penicillin & Ampicillin & Cephalothin & Tetracycline & Chloramphenicol & Kanamycin & Colistin & Gentamicin \\
\hline $\begin{array}{l}\text { Patient } \\
\quad(2 \text { isolates })\end{array}$ & $>50$ & $>50$ & $>50$ & 0.8 & $0 \cdot 8$ & 25 & $>50$ & $>6^{1}$ \\
\hline $\begin{array}{l}\text { MIC } \\
\text { A. hydrophila }\end{array}$ & $>50$ & $>50$ & $\geqslant 50$ & $\leqslant 0.8$ & $\leqslant 3$ & 12 & $<0.4$ & $\leqslant 3$ \\
\hline $\begin{array}{l}\text { Percentage of } 7 \text { isolates } \\
\text { inhibited at indicated } \\
\text { MIC }\end{array}$ & 71 & 57 & 86 & 86 & 100 & 86 & 43 & 100 \\
\hline $\begin{array}{l}\text { E. coli } \\
\text { No isolates } \\
\text { Percentage isolates }\end{array}$ & 814 & 813 & 813 & 812 & 599 & 811 & 807 & 430 \\
\hline $\begin{array}{l}\text { inhibited at indicated } \\
\text { MIC }\end{array}$ & 15 & 12 & 13 & 3 & 4 & 76 & 98 & 69 \\
\hline
\end{tabular}

Table Antibiograms expressed as minimal inhibitory concentration

${ }^{1}$ Only one isolate tested.

antibiogram of the patient's organisms except for the response of three of the seven isolates to colistin.

Inhibition by low concentrations of chloramphenicol and tetracycline is noteworthy and suggests that these agents may be the drugs of choice in therapy of Aeromonas hydrophila infection pending the results of a specific antibiogram.

\section{References}

MacLowry, J. D., Jaqua, M. J., and Selepak, S. T. (1970a). Detailedmethodology and implementation of a semiautomated seriads dilution and microtechnique for antimicrobial susceptibilit testing. Appl. Microbiol., 20, 46-53.

MacLowry, J. D., Jaqua, M. J., and Selepak, S. T. (1970b). PersonaT communication; data in preparation for publication. 